\section{Rhythm book never swings}

Biological Clocks in Marine Organisms: The Control of Physiological and Behavioural Tidal Rhythms. By J. D. Palmer. Pp. $x+173$. (Wiley: New York and London, June 1974.) $£ 6.85$.

IN this book the author attempts to bring the problems and fascinations of the study of biological clocks in marine organisms before a wide audience. The book is, in fact, an expansion of the author's recent review in the journal Biological Reviews and is the first of its kind.

It is about the way in which various activities of a whole range of marine animals are instigated and controlled by some facet of the rhythm of the tides. An essential aim of any animal is to maximise the efficiency of, for example, its feeding so that it takes the greatest advantage of food when available. Thus, an intertidal animal which is quiescent when the tide is out undergoes changes when the tide is due to cover it so that it is absolutely ready to feed when water covers it. This preparatory behaviour persists for a period when the animal is removed to a laboratory, demonstrating its innate character. The description of a variety of phenomena of this kind, and the mechanisms behind them, form the substance of this book.

To be completely successful in attracting a wide audience requires subject matter of considerable fascination, a style of writing which is both easily comprehensible and stimulating, and illustrations of high quality. In order to attract future researchers the gaps in present knowledge require emphasis, as do promising lines of research. Unfortunately, although some of these ideals are approached quite closely in some respects the book seems to fall short of its target.

The book is quite comprehensive and incorporates almost all of the significant literature on the subject. It is very well illustrated and the style is generally clear once technical terms are mastered. A very good feature is the summary at the end of each chapter, and the bibliography is of value to the nonspecialist.

In spite of that and the obvious expertise of the author, however, I was not greatly stimulated by his treatment of the available material, which seemed rather mundane. I feel that although the general reader is likely to be attracted by the subject he will not be altogether attracted by its presentation; and whether any potential researcher would be fired with enthusiasm is debatable. Dr Palmer does point out the gaps in current knowledge but he never makes one feel that life would

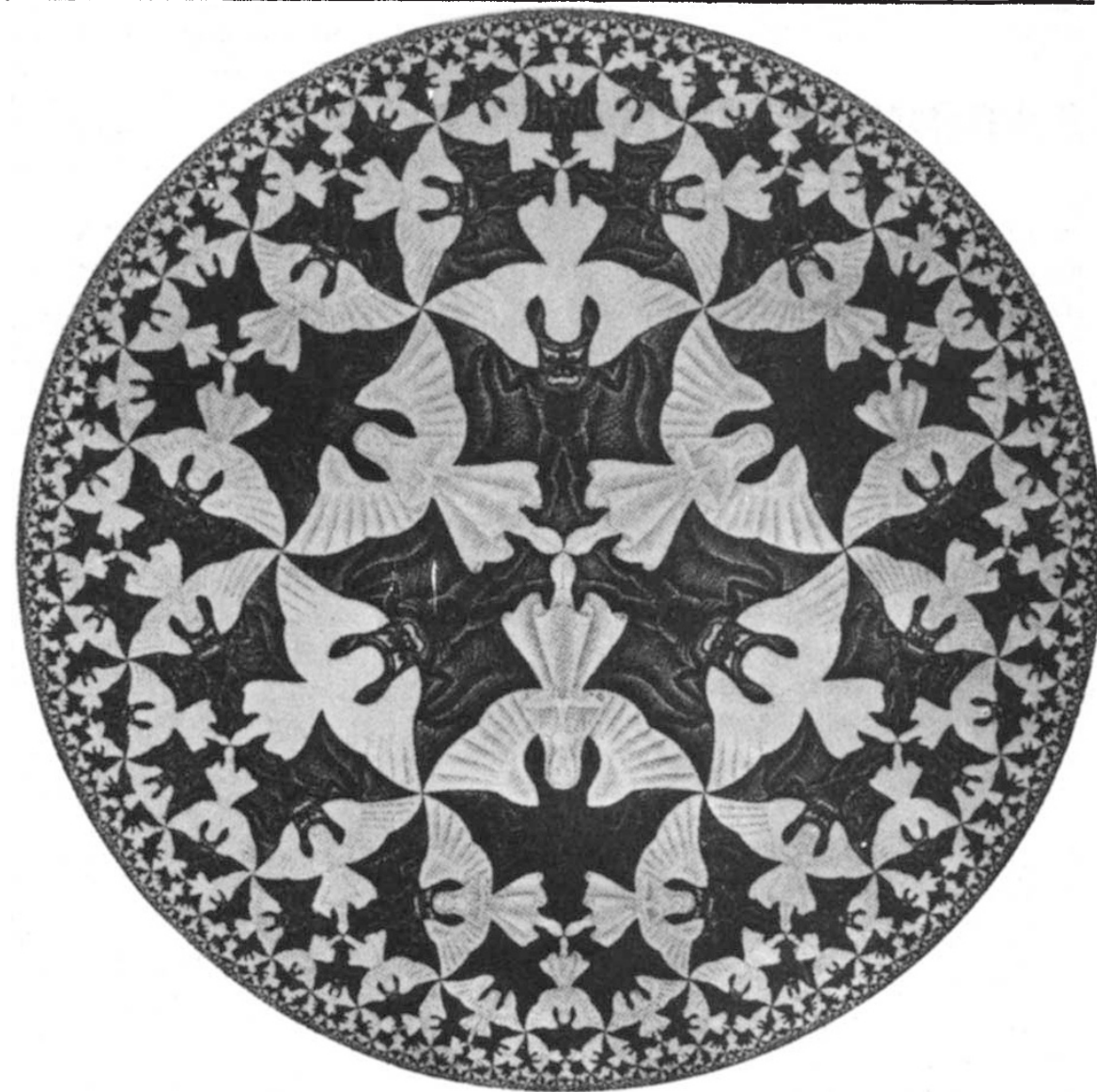

"Circle Limit IV (Heaven and Hell)", a woodcut by Maurits C. Escher. Devils and angels alternate repeatedly and compete for attention. From Image, Object, and Illusion. (Readings from Scientific American.) Introductions by Richard Held. Pp. 137+155 illustrations. (Freeman: San Francisco and London, 1974.) Cloth, $\$ 8.00$; paper, $\$ 4.50$.

be incomplete without further knowledge of this or that phenomenon.

The book is undoubtedly a very useful contribution to literature and should be in every biology department's library but its contribution lies in its value as a storehouse of information rather than as a source of inspiration. Its price will probably mean that few other than libraries will buy it.

R. H. Emson

\section{Pain}

Recent Advances on Pain. Edited by John J. Bonica, P. Procacci, and C. A. Pagni. Pp. xv+373. (Charles C. Thomas: Springfield, 1974.) \$19.75.

THIS excellent book contains the proceedings of a symposium on the pathophysiology and clinical aspects of pain held in Florence in April 1972. The contributors were eminent men, representing various specialties, from Italy, Switzerland, North America and the United Kingdom.

The main message of the symposium is reflected by its broad coveragenamely, that for both the study of pain and its clinical management a multidisciplinary approach is needed. The subject matter included the neurophysiology of pain, endogenous painproducing substances, analgesic blocks and surgery for the relief of pain, pain threshold measurements in man, and operant conditioning for chronic pain. In addition, there is a paper by Professor Bonica on the organisation and function of a pain clinic.

This list, although giving some idea of the scope of this book, does not do justice to the vist amount of information it contains. For those interested in migraine there is a fascinating contribution by Professor Sicuteri, and there are some thoughts on the roles of acupuncture, radiostimulators and inhibitory mechanisms in the relief of pain.

In order that the firuits of many years of research undertaken by the contributors be disseminated as widely as possible this book should be read not only by those whose research is directed towards the study of pain but also by those who are in any way connected with the relief of suffering.

The editing of a book of this kind must be a vast undertaking; none the less, it is a pity that there are so many errors. Apart from spelling mistakes and what seem to be mistakes arising from misread handwriting it is strange that there are 65 references at the end of Chapter VHII when only nine are mentioned in the text.

Diana R. Haslam 